\title{
Time Pressure Increases Component Fluency of Creativity
}

\author{
Elsa Tamara Shalsabila ${ }^{1 *}$, Elvara Wibowo Putri ${ }^{1}$, Hanifah Hathimadinda Hosen ${ }^{2}$, Selvia \\ Ernas $^{3}$, Angelica Tabitha Hasibuan ${ }^{4}$, and Lucia Voni Pebriani ${ }^{5}$ \\ 1,1.2.3.4.5 Psychology Department, Padjadjaran University, Sumedang, Indonesia \\ *E-mail: elsa.shalsabila@gmail.com
}

\begin{abstract}
An assignment has become a familiar thing for students, and it is often given with deadline. For some students, the deadline is perceived as pressure. However, some other students claim that the deadline existence pushes them to come up with more ideas. According to Guilford's theory, these more ideas are an example of fluency in the creativity components. This study aims to examine whether time pressure increases fluency component of creativity. The creativity was measured using Guilford's Alternative Uses Test. Data were obtained using probability sampling method from 34 first-year students of Padjadjaran University, majoring in psychology. Participants were randomly assigned to two groups, control and experimental. Using independent sample $t$ test with a confidence interval of $90 \%$, the result showed that time pressure increased fluency component of creativity $(t=-1.616, \mathrm{p}<0.1)$.
\end{abstract}

Keywords: alternative uses test, creativity, fluency, time pressure

\section{Introduction}

Franken (1993) defines creativity as the tendency to generate or recognize ideas, alternatives, and possibilities that may be useful in solving problems, communicating with others, and entertaining ourselves and others (Franken, 1993). According to Guilford's Alternative Uses Test, there are four components of creativity. The first one is originality, which is how unusual the ideas are. The second one is flexibility, which means the range of ideas in different domains and categories. Elaboration is the third one that represents the level of detail and development of the ideas. The last component is fluency, which constitutes how many ideas participants can think. This study would only focus on fluency component, or the total number of ideas participants could think of. Even though originality is often considered as the most critical component in creativity, but at most of the time, fluency is highly correlated with, or even able to predict originality (Shiu, 2014). Because of that, Shiu (2014) states that giving generating ideas task can use only fluency component.

There are several types of fluency (Silvia, 2013): (1) Word Fluency, the ability to rapidly produce words that have specific phonemic, structural, or orthographic characteristics; (2) Associational Fluency, which is the ability to rapidly produce words or phrases associated in meaning (semantically associated) with a given concept; (3) Expressional Fluency, which means the ability to rapidly think of and organize words or phrases into meaningful complex ideas under high general or more specific cueing conditions; (4) Ideational 
Fluency, or the ability to rapidly produce a series of thoughts, words, or phrases related to particular situation or object in which quantity is emphasized instead of quality; (5) Letter Fluency or Phonemic Fluency, which is the ability to generate words beginning with a single letter, most commonly F, A, and S; (6) Associative Flexibility; and (7) Dissociative Ability.

Previous researchers found that there are several factors influencing creativity. Among others are: 1) space, in which creativity has no positive influence if the undisturbed space is not provided; 2) pressures, such as excessive workload pressure and challenge due to intrinsic nature; 3) intelligence; 4) age, as creativity found to be decreasing with age, unless an individual is intentionally creative; 5) personality, in which creativity usually develop more in an individual who highly values the aesthetic qualities of their experiences, has interest to creativity, attracts to complexity, independent of judgment, autonomous, intuitive, self-confident, able to resolve conflicting traits in self, and believe that oneself is creative; and 6) time, in which creativity has no positive influence if the right amount of time is not provided. Having time and pressure as two of several factors that influence creativity, this study tried to examine a phenomenon based on those two factors.

Informal education settings, students have been exposed to assignments from their teachers ever since elementary school up until university level. Frequently, teachers set the deadline for the tasks. This deadline might be perceived by students as time pressure. For some students, this kind of pressure can be viewed as a challenging situation that may even lead to stress. Time pressure is perceived as a stressor when one has to finish something with the deadline (Schreuder, 2011), which according to Beevis (1999) is the time after
$70 \%$ to $85 \%$ of the total given time. Cognition Activation Theory of Stress (CATS) could explain this phenomenon. According to CATS, a person will feel stressed whenever there is a difference between their set value and the actual value (Eriksen \& Ursin, 2002). An actual value is the ability to answer questions or to finish task purely based on the time one needs. Meanwhile, the set value is the ability to answer questions or to complete work with the presence of deadlines as the time pressure.

However, there are students claim that due to the deadlines, not only they do the assignments faster, but also they come up with many new ideas while when doing them. According to Dual Pathway to Creativity Model (De Dreu, Baas, \& Nijstad), creativity is a function of cognitive flexibility and persistence. Many studies have tested this model, in which participants were asked to come up with creative ideas. Ultimately, this model explains how different moods affect creativity. In the first path, creativity could be activated with positive mood. It will produce cognitive flexibility. The second path is producing creativity through activating negative mood. It will produce cognitive perseverance. With a challenging stressor, the activated mood is a positive one that will then improve one component of creativity, that is fluency.

Activation would be done by providing information. The information would be received auditorily by in the form of time reminder. This reminder acts as the procedure of time pressure and will be received by participants' auditory sensory system. Once the information goes into the brain, the time reminder will be perceived as a stressor because there is a discrepancy between the set value and the actual value of the participants. 
Figure 1.

Process of Increasing Creativity

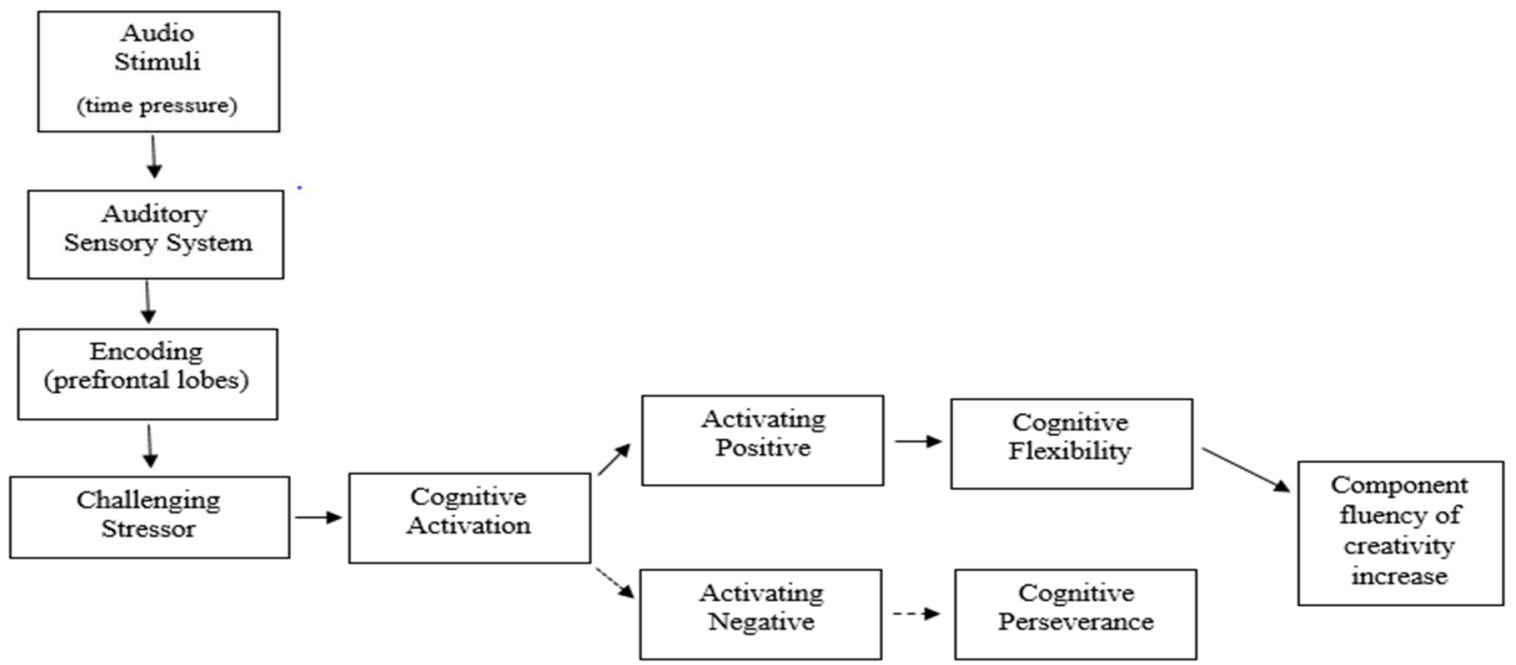

Based on those backgrounds, authors wanted to know whether time pressure could increase the creativity of undergraduate students. Moreover, this phenomenon was in line with the reality captured in the assessment conducted to undergraduate Psychology students in Universitas Padjadjaran, our institution. The result of previous assessment showed that $95 \%$ of students were always challenged by the deadline given by their lecturers. First-year Psychology students in Padjadjaran University have a different curriculum from their seniors. In the new curriculum, they already have had several classes that may be perceived hard for the first year. Besides that, they have one class in which they have a weekly assignment with a deadline that demanded them to have high creativity. Therefore, there is a high possibility that the first-year Psychology students experience higher stress. It became the reason for choosing them as participants of this experiment. Moreover, they have not learned Cognitive Psychology and Experimental Psychology subjects, so we assume that there will be no bias during the experiment.

\section{Methods}

Sample. Data collection was carried out through questionnaire a few days before the experiment was conducted in Psychology
Faculty of Padjadjaran University. A sample of 34 first-year undergraduate students met some criterions which were they should have GPA scale around 3 to 4 and should feel challenged to do assignments with deadlines. The sample that took part in this study was comprised of 6 males $(17.65 \%)$ and 28 females $(82.35 \%)$. They were randomly assigned to a control group as many as 17 participants and an experimental group as many as 17 participants

Procedures. Participants who had filled out informed consent were asked to write down realistic uses as many as possible of 5 common objects, which are a bottle, newspaper, umbrella, mug, and slipper. Each object was shown for 90 seconds based on trying out result in which the average time needed to mention the usefulness of each object in the try out was approximately 90 seconds. When participants heard the instruction 'next,' they should move on to the next object for another 90 seconds, and so forth until the fifth object. For experiment group, there were time reminders as the participants were reminded at the 65 th seconds ( $70 \%$ of the total time available for the tasks) and 80 th seconds $(85 \%$ of the total time available for the tasks. for each object as the pressure of time). At the end of the experiment, participants were asked to rate 
from the scale of 1 to 5 about how challenged they felt during the experiment. They were also requested to explain the reason why they chose the specific number on the scale. Lastly, they were required to write down how their mood was, whether positive or negative, during the experiment as well as the elaboration.

Measures. The Alternative Uses Test was the revised concept of "divergent thinking" which was first proposed by J. P. Guilford in 1950s when he noticed that creative people tend to exhibit divergent thinking more. He thus associated divergent thinking with creativity. This test, therefore, was used to measure creativity and it is usually time constrained. This test asks the participants to think of as many uses as possible for a common object.

Data Analysis. The data of this study was analyzed in two ways. First, the data was computed in SPSS version 22 using T-Test Two Independent Sample as the primary analysis. Second, the secondary analysis was processed through a questionnaire regarding the participants' mood and state of being challenged. The computed data is the total answer of the objects' usefulness mentioned by each participant. Data were obtained by testing two sample groups to see if there was an increase in the average score of answers between the control and the experimental group. Measurement scale on the variables measured in this study is interval because the existing data in the form of scores has a continuum range and the value of zero in the assessment is not absolute.

\section{Results}

Based on the research it was obtained that with $\alpha=0.1$ and $F=0.046$, the experiment group had higher mean score $(\mathrm{M}=4.565, \mathrm{SD}=$ 1.11942), and the control group had lower mean score $(\mathrm{M}=3.918, \mathrm{SD}=1.1403)$. With $0.058 \mathrm{p}$-values, the null hypothesis was rejected which indicates that $p$-value is less than $\alpha(0.058<0.1)$. Based on the secondary result, it was obtained that participants from experiment group experienced positive mood (12 participants) more than the control group (5 participants) during the experiment.

Table 1.

Primary Result

\begin{tabular}{lll}
\hline Group & Mean & SD \\
Esperiment & 4.565 & 1.11942 \\
Control & 3.918 & 1.1403 \\
\hline
\end{tabular}

Table 2.

Secondary Result

\begin{tabular}{lll}
\hline Group & Positive Mood & $\begin{array}{c}\text { Negative } \\
\text { Mood }\end{array}$ \\
Control & 5 & 12 \\
Experiment & 12 & 5 \\
\hline
\end{tabular}

Based on Table 1, it was obtained that the null hypothesis was rejected which concludes that time pressure increases component fluency of creativity. It was supported by the secondary result, as shown in Table 2., that the number of participants in experiment group who got treatment (which is being given time pressure) showed positive mood more during the experiment. This finding proves that time pressure that was perceived as challenged stressor would activate positive mood to create cognitive flexibility. Therefore, in the end, the component fluency of creativity will be improved.

\section{Discussion}

First-year Psychology students in Padjadjaran University perceive assignments as both motivation and pressure, hence at the end their creativity increases. This finding fits the theory of Cognitive Activation Theory of Stress which states that a person will feel stressed whenever there is a discrepancy between set value, which in this case is the deadline, and the actual value which is the students' real ability to finish something. 
We conducted this study based on the inspiration from the phenomenon of assignments with a deadline as the time pressure that could make some students finish them creatively while some others do not. Hence, the purpose of the current study was to investigate the possibility of an increase in creativity precisely resulted from time pressure. In addition to this aim, based on Alternative Uses Test, the authors specified component fluency as what the authors would measure. The experiment's results support the hypothesis that time pressure increases the component fluency of creativity. This study's finding support for the Dual Pathway to Creativity Model theory. In addition to the main finding, we verified that more participants experienced positive mood in the experimental group. On the other hand, there were more participants experienced negative mood. These data showed more proofs to support the theory, regarding on how creativity stimulated.

\section{Conclusion and Limitation}

A study explaining component fluency of creativity has never been done in Indonesia, and thus the present study aimed to examine the possibility of time pressure in increasing the component fluency of creativity. The findings reveal that time pressure increases the component fluency of creativity among firstyear Psychology students of Padjadjaran University.

However, there are several limitations to the current study. Firstly, the total number of sample is not large enough to make the study representative, and the age range is relatively homogeneous. Hence, it may be necessary for future studies to use large sample consisting more diverse age range. Secondly, personality is one of several factors that influences creativity, but in this study, the personality of the sample was not controlled. Therefore, there is a need to control the personality of the participants in future research. Thirdly, the findings did not explain whether the creativity increase has precisely resulted from the cognitive flexibility and cognitive perseverance. It was because participants were only asked how their mood was only at the end of the test. Therefore, this issue awaits further research that will ask about the mood both at the beginning and at the end of the test to have high internal validity. In conclusion, more researches about time pressure in scientific studies are needed as a reference for lecturers in term of setting the deadlines of assignments.

\section{Acknowledgments}

We would like to thank Prof. Dr. Wilis Srisayekti as the coordinator of Experimental Psychology class.

\section{References}

Amabile, Teresa M. et al. (2002). Time Pressure and Creativity in Organizations: A Longitudinal Field Study. Harvard Business School., 1, 1-26.

Cold Weather Workers Safety Guide. (2017). Thermal Comfort for Office Work. Retrieved from https://www.ccohs.ca/oshanswers/phys_agents/ther mal_comfort.html

Christensen, Larry B. (2006). Research Methodology $\left(10^{\text {th }}\right.$ Ed.). Boston: Allyn \& Bacon.

Creative Huddle. (2017). The Alternative Uses Test. Retrieved from http://www.creativehuddle.co.uk/the-alternative$\underline{\text { uses-test }}$

Dippo, Caitlin. (2013). Evaluating The Alternative Uses Test of Creativity. Minneapolis: University of Minnesota Twin Cities.

Dow, Gayle. (1967). Guilford's Alternative Uses Task. Indiana University. Retrieved from http://www.indiana.edu/ bobweb/r546/modules/cre ativity/creativity tests/guilford ues task.html

Franken, Robert E. (1993). Human Motivation ( $3^{\text {th }}$ Ed.). CA: Brooks/Cole.

Franken, R. E. (n.d.). What Is Creativity? California State University, Northridge. Retrieved from https://www.csun.edu/ vcpsy00h/creativity/define. $\underline{\mathrm{htm}}$

Ihsan, Muhammad. (2016). Teknik Pengambilan Sampel dan Penjelasannya Lengkap. Retrieved from http://pajaa.com/teknik-pengambilan-sampel/ 
Kelvianto, Marvin, et al. (2016). Pengaruh Pemberian Time Pressure Terhadap Kemampuan Mengingat Istilah Psikologi Pada Mahasiswa Fakultas Psikologi Universitas Padjadjaran Angkatan 2015. Skripsi. Universitas Padjadjaran.

Koruklu, Nermin. (2014). Personality and Social Problem-Solving: The Mediating Role of SelfEsteem. Adnan Menderes University. 15. 482-486. doi 10.12738/estp.2015.2.2601

Lynette, Rachel. (2009). Creative Thinking: Fluency. Retrieved from http://minds-inbloom.com/creative-thinking-fluency/

Matlin, Margaret W. (2009). Cognition ( $7^{\text {th }}$ Ed.). USA: John Wiley \& Sons, Inc.

Munro, John. (n.d.). Insights Into The Creativity Process: The Components of Creativity. Retrieved from https://students.education.unimelb.edu.au/selage/pu b/readings/creativity/UTC_the_components_of_cr e.pdf

Narayana, B. V. L. (2012). Factors Influencing Creativity and Innovation---Creativity. Springer Briefs in Applied Science and Technology. doi: 10.1007/978-3-642-38646-6_2

Nijstad. Bernard A. (n.d.). The Dual Pathway To Creativity Model: Creative Ideation As A Function of Flexibility And Persistence. University of Groningen.

Orfus, Shauna. (2008). The Effect Test Anxiety and Time Pressure on Performance. The Huron University College Journal of Learning and Motivation, Vol. 46, 1, 7.
Prabhu, Veena. (2008). Creativity and Certain Personality Traits: Understanding The Mediating Effects of Intrinsic Motivation. Auburn University.

Saxena, Shalini. (2016). Factors That Influence Creativity. retrieved from http://passionconnect.in/articleview/articleid/Factor s-That-Influence-Creativity

Schreuder, Ernestina J. A. \& Tina Mioch. (2011). The Effect of Time Pressure and Task Completion on The Occurrence of Cognitive Lockup. The Netherlands: University of Utrecht.

Shiu, Eric. (2014). Creativity Research An InterDisciplinary and Multi-Disciplinary Research Handbook. New York: Routledge Taylor \& Francis Group.

Silvia, Paul J., et al. 2013. Verbal Fluency and Creativity: General and Specific Contributions of Broad Retrieval Ability (Gr) Factors To Divergent Thinking. United States: University of North Carolina.

Simon. (2013). The Cognitive Activation Theory of Stress. Retrieved from http://reflectd.co/2013/05/03/the-cognitiveactivation-theory-of-stress/

Sung, Sun Young \& Choi, Jin Nam. (2009). Do Big Five Personality Factors Affect Individual Creativity? The Moderating Role of Extrinsic Motivation. Seoul National University.

Worley, Chen Shu J. (2015). Understanding How To Nurture Creativity. New York: Touro College. 